ORNL/TM--12319

DE93 010834

NONLINEAR ANALYSIS OF HYDRAULIC BUCKLING INSTABILITY

OF ANS INVOLUTE FUEL PLATES

W. K. Sartory

March 1993

Prepared by the

OAK RIDGE NATIONAL LABORATORY

Oak Ridge, Tennessee 37831

managed by

MARTIN MARIETTA ENERGY SYSTEMS, INC.

for the

U.S. DEPARTMENT OF ENERGY

under contract DE-AC05-84OR21400 
ACKNOWLEDGMENTS $\ldots \ldots \ldots \ldots \ldots \ldots \ldots \ldots \ldots \ldots \ldots \ldots \ldots \ldots \ldots$

ABSTRACT $\ldots \ldots \ldots \ldots \ldots \ldots \ldots \ldots \ldots \ldots \ldots \ldots \ldots \ldots \ldots \ldots \ldots \ldots \ldots$

1. INTRODUCTION $\ldots \ldots \ldots \ldots \ldots \ldots \ldots \ldots \ldots \ldots \ldots \ldots \ldots \ldots \ldots \ldots \ldots$

2. HYDRAULIC CHANNEL ELEMENT $\ldots \ldots \ldots \ldots \ldots \ldots \ldots \ldots \ldots \ldots \ldots$

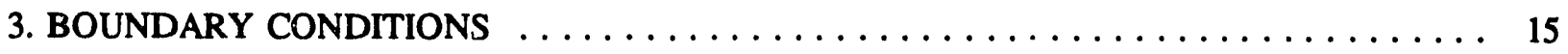

4. ANALYSIS OF AN IMPERFECT CHANNEL $\ldots \ldots \ldots \ldots \ldots \ldots \ldots \ldots \ldots$

5. NONLINEAR DEFLECTION RESULTS $\ldots \ldots \ldots \ldots \ldots \ldots \ldots \ldots \ldots \ldots \ldots$

6. SUMMARY AND CONCLUSIONS $\ldots \ldots \ldots \ldots \ldots \ldots \ldots \ldots \ldots \ldots \ldots \ldots$

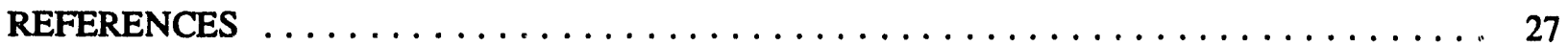




\section{ACKNOWLEDGMENTS}

The author wishes to express his thanks to F. W. Swinson for discussions of his experimental studies of ANS fuel plate stability and for reviewing this report, to C. R. Luttrell for a quality assurance review of the computer program written to implement the hydraulic channel user element and for reviewing this report, and to G. T. Yahr who directed this project. 


\title{
NONLINEAR ANALYSIS OF HYDRAULIC BUCKLING INSTABILITY OF ANS INVOLUTE FUEL PLATES
}

\author{
W. K. Sartory
}

\begin{abstract}
The hydraulic buckling instability of the involute fuel plates and hydraulic coolant channels in the Advanced Neutron Source (ANS) uranium fission reactor is analyzed nonlinearly using the commercial ABAQUS finite element computer program for the fuel plates in conjunction with a user-written element for the two-dimensional fluid flow in the coolant channels.

This methodology has been used for several purposes, including determination of the effect of the aluminum-clad plate plastic behavior and the effect of three-dimensional plate temperature distributions on hydraulic buckling. The present report concentrates on a study of the effect of hydraulic channel imperfections on buckling. The specific form of imperfection considered is an error in fluid channel thickness that is uniform within any one channel but that varies from one channel to the next.

The calculated bifurcation (linear buckling) coolant velocity is about $45 \mathrm{~m} / \mathrm{s}$, whereas the present design coolant velocity is $25 \mathrm{~m} / \mathrm{s}$. At the design velocity, the calculated fluid-induced plate deflection due to the imperfection is somewhat less in magnitude and opposite in direction from the imperfection itself.
\end{abstract}

\section{INTRODUCTION}

The Advanced Neutron Source ${ }^{1}$ (ANS) is a highly enriched uranium fission reactor presently under design at the Oak Ridge National Laboratory to produce neutrons for research use. One primary objective is to achieve a high neutron flux. To meet this objective, a small reactor core with a high fission heating density is required, which leads the designers to seek high coolant velocities to remove the heat.

Since the work of Stromquist and Sisman in $1948,{ }^{2}$ it has been known that very high flow velocities past fuel plates can cause the plates to deform, buckle, and collapse. Excessive fuel plate deformation can impede coolant flow and heat removal and thus must be avoided in the reactor design. For the ANS, both analytical and experimental ${ }^{3}$ work is under way to ensure that the plate deformation remains within satisfactory limits. 
An interesting explanation of the flow-induced buckling was proposed by Miller, ${ }^{4}$ who coupled a simplified plate deformation equation with a one-dimensional Bernoulli's equation for the fluid. He argued that if a small perturbation (because of an initial plate imperfection or any other source) caused two adjacent plates to move closer together at some location, then the fluid velocity between them at that location would increase. According to Bernoulli's equation, the fluid pressure between the plates would then drop, tending to force the plates even closer together. At a certain critical velocity, the fluid forces tending toward plate collapse would exceed the elastic forces tending to huld the plates in their design configuration, and the plates would buckle.

Miller studied both flat and uniformly curved cylindrical plates* with different boundary conditions along their supported edges. Patterned after the successful High Flux Isotope Reactor, ${ }^{5}$ the ANS will use fuel plates with an involute shape (see Fig. 1). Gwaltney and Luttrell ${ }^{6}$ therefore extended Miller's theory to involute plates by coupling elastic finite-element models of the plates with Bernoulli's equation for the fluid. They found that the involute plates were much more stable than flat plates of the same span because of the stiffening effect of their curvature, but not as stable as cylindrical plates with the same average curvature.

More detailed fluid modeling was carried out, for example, by Scavuzzo ${ }^{7}$ and by Smissaert ${ }^{8}$ for flat plates.

For involute plates, Sartory ${ }^{9}$ used a combination of Galerkin's method and the method of lines to develop a linearized (infinitesimal perturbation) model (including detailed two-dimensional modeling of the fluid flow) that was used to predict both the buckling threshold and natural vibrational frequencies and mode shapes for the fluid-plate system.

Since the publication of Ref. (9), a variety of more complicated requirements have appeared that require a more flexible computational approach. For example, (1) the effect of detailed three-dimensional temperature profiles within the fuel plate on hydraulic buckling and (2) the effect of plastic behavior and of large (noninfinitesimal) imperfections in the fluid channel dimensions on plate deflection need to be determined. All of these complications in plate

"There is a conflict in terminology here. In solid mechanics, a plate is understood to be flat, and a curved plate is called a shell. In nuclear design practice, the term fuel plate is used regardless of curvature. In the present report, the curved involute fuel plates of the ANS and similar curved fuel plates of other reactors will be referred to either as plates or shells. 

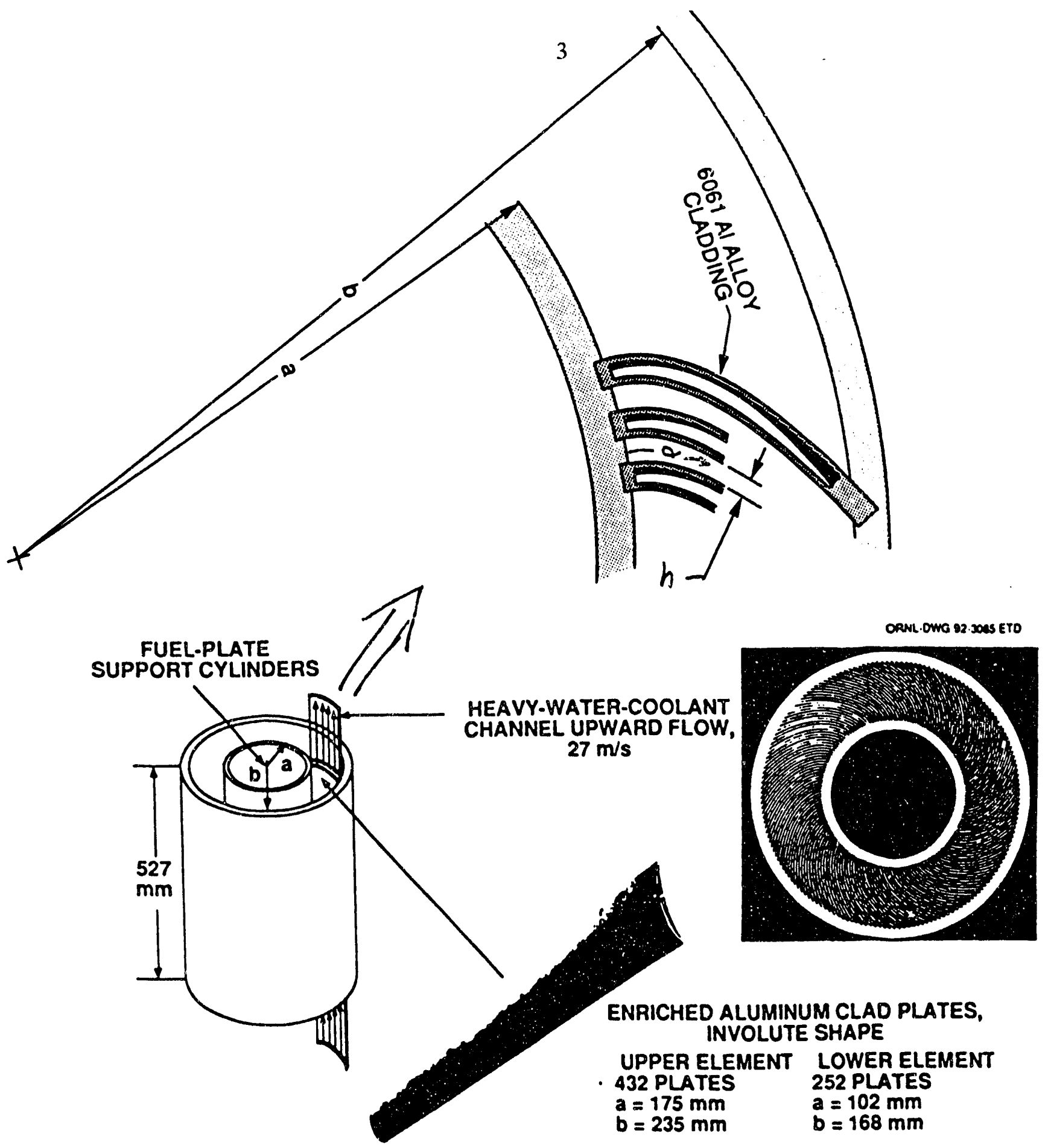

Fig. 1. Illustration of array of involute fuel plates in cylindrical sidewalls. The side plate radii, $a$ and $b$, are referred to in this report as the inner and outer radii of the involute, respectively. The inset shows the direction of the $\alpha$ axis. 
modeling are readily treated by finite element structural analysis programs that are commercially available. The program ABAQUS was, therefore, chosen for the present work. However, ABAQUS lacks a specialized two-dimensional hydraulic channel fluid element, so a hydraulic channel user element was written and coupled to a standard ABAQUS curved-shell element to provide the necessary capability. 


\section{HYDRAULIC CHANNEL ELEMENT}

The two-dimensional fluid equations used in the present work may be obtained by mass and momentum balances on a rectangular differential element of a thin channel with curvature ignored. The equations are as follows:

$$
\begin{gathered}
\frac{\partial \rho h}{\partial t}+\frac{\partial \rho h v_{1}}{\partial \alpha}+\frac{\partial \rho h v_{2}}{\partial z}=0, \\
\frac{\partial \rho h v_{1}}{\partial t}+\frac{\partial \rho h v_{1}{ }^{2}}{\partial \alpha}+\frac{\partial \rho h v_{1} v_{2}}{\partial z}=-h \frac{\partial p}{\partial \alpha}-f \rho\left(v_{1}{ }^{2}+v_{2}{ }^{2}\right)^{1 / 2} v_{1}, \\
\frac{\partial \rho h v_{2}}{\partial t}+\frac{\partial \rho h v_{1} v_{2}}{\partial \alpha}+\frac{\partial \rho h v_{2}^{2}}{\partial z}=-h \frac{\partial p}{\partial z}-f \rho\left(v_{1}{ }^{2}+v_{2}{ }^{2}\right)^{1 / 2} v_{2},
\end{gathered}
$$

where $\rho$ is the (constant) fluid density, $h$ is the channel thickness, $t$ is time, $v_{1}$ and $v_{2}$ are the transverse and axial comporients of fluid velocity averaged through the thickness of the channel, $\alpha$ and $z$ are the transverse and axial coordinates ( $\alpha$ is actually an arclength coordinate that curves out along the midsurface of the involute channel), $p$ is the fluid pressure, and $f$ is the Fanning friction factor. Because the Fanning friction factor varies only weakly with the local Reynolds number, it has been treated both as an approximate constant and as a prescribed function of the unknown channel thickness and velocities in different phases of the present work. In this derivation, $f$ will be treated as a constant for simplification, but the numerical results presented allow for perturbations of $f$ due to perturbations of coolant velocity and channel thickness.

Equations (1)-(3) are strictly applicable to an uncurved channel geometry; they do not capture any effect of the involute shape of the ANS channels in the fluid behavior. It is expected that the uncurved channel approximation will be satisfactory as long as the average channel thickness is much smaller than the average channel radius of curvature. One effect that is notably omitted is the centrifugal force because of fluid flowing around the curved involute. Adding such a centrifugal term in future work may prove worthwhile. In addition, the two-dimensional approximation involves omission of some effects that have never been studied in detail. 
ABAQUS solves nonlinear equations using Newton's method, which involves repeated application of a linearized perturbation about an (arbitrary but known) approximate solution for each variable. Thus we introduce the following perturbations:

$$
\begin{aligned}
& v_{1}=\bar{v}_{1}+v_{1}{ }^{\prime}, \\
& v_{2}=\bar{v}_{2}+v_{2}{ }^{\prime}, \\
& p=\bar{p}+p^{\prime},
\end{aligned}
$$

where the barred quantities are the known current approximations to the solution, and the primed quantities are the unknown infinitesimal Newton corrections to the solution. In addition, the fluid channel thickness, $h$, is related to the displacements of the surrounding shells in the present work by the approximate equation:

$$
\begin{aligned}
h & =h_{0}+\hat{n} \cdot\left(\bar{x}_{2}-\bar{x}_{1}, \bar{y}_{2}-\bar{y}_{1}, \bar{z}_{2}-\bar{z}_{1}\right) \\
& +\hat{n} \cdot\left(x^{\prime}{ }_{2}-x^{\prime}{ }_{1}, y^{\prime}{ }_{2}-y^{\prime}{ }_{1}, z^{\prime}{ }_{2}-z^{\prime}{ }_{1}\right),
\end{aligned}
$$

where $h_{0}$ is the unperturbed fluid channel thickness, $h$ is the local unperturbed normal vector to the fluid channel midsurface, $\bar{x}_{2}$ is the x-component of the known current estimate of the shell deflection for shell-2, $x_{2}^{\prime}$ is the $x$-component of the unknown infinitesimal correction to the shell deflection for shell-2, and the tripiets in parentheses are representations of 3-vectors that are used to form dot products with the normal.

In the present work, Eq. (7) is applied node-by-node as if corresponding nodes for the fluid channel and for the two plates always lie along the same perpendicular through the channel. That condition is exactly correct at the root of the involute but gradually accumulates an error for nodes away from the root. Because the resulting error goes to zero as the channel and plate thicknesses go to zero, this can be interpreted as a part of the thin-channel approximation. Equations (4)-(7) are substituted into Eqs. (1)-(3). Terms that are of order 0 or 1 with respect to primed quantities are collected, and quantities that are of higher erder are discarded in accordance with the rules of perturbation theory. If Newton's iteration converges, then the higher order terms become smaller as the 
iteration proceeds and will become negligible if the iteration is carried far enough. If Newton's method fails to converge, then the iteration must be discarded in any case. The resulting steady-state perturbation equations are as follows:

$$
\begin{aligned}
& \rho \bar{h}^{\partial v_{1}{ }^{\prime}} \frac{\partial \bar{v}_{1}}{\partial \alpha} h^{\prime}+\rho \bar{h} \frac{\partial v_{2}^{\prime}}{\partial z}+\rho \frac{\partial \bar{v}_{2}}{\partial z} h^{\prime}+\rho \bar{v}_{1} \frac{\partial h^{\prime}}{\partial \alpha}+\rho \frac{\partial \bar{h}}{\partial \alpha} v_{1}^{\prime} \\
& +\rho \bar{v}_{2} \frac{\partial h^{\prime}}{\partial z}+\rho \frac{\partial \bar{h}^{2}}{\partial z} v_{2}^{\prime}=-\left[\rho \bar{h} \frac{\partial \bar{v}_{1}}{\partial \alpha}+\rho \bar{h} \frac{\partial \bar{v}_{2}}{\partial z}+\rho \bar{v}_{1} \frac{\partial \bar{h}}{\partial \alpha}+\rho \bar{v}_{2} \frac{\partial \bar{h}}{\partial z}\right], \\
& \rho \bar{h} \bar{v}_{1} \frac{\partial v_{1}^{\prime}}{\partial \alpha}+\rho \bar{h} \frac{\partial \bar{v}_{1}}{\partial \alpha} v_{1}^{\prime}+\rho \bar{v}_{1} \frac{\partial \bar{v}_{1}}{\partial \alpha} h^{\prime}+\rho \bar{h} \bar{v}_{1} \frac{\partial v_{2}^{\prime}}{\partial z} \\
& +\rho \bar{h} \frac{\partial \bar{v}_{2}}{\partial z} v_{1}^{\prime}+\rho \bar{v}_{1} \frac{\partial \bar{v}_{2}}{\partial z} h^{\prime}+\rho \bar{h} \bar{v}_{1} \frac{\partial v_{1}^{\prime}}{\partial \alpha}+\rho \bar{h} \frac{\partial \bar{v}_{1}}{\partial \alpha} v_{1}^{\prime} \\
& +\rho \bar{v}_{1} \frac{\partial \bar{v}_{1}}{\partial \alpha} h^{\prime}+\rho \bar{h} \bar{v}_{2} \frac{\partial v_{1}^{\prime}}{\partial z}+\rho \bar{h} \frac{\partial \bar{v}_{1}}{\partial z} v_{2}^{\prime}+\rho \bar{v}_{2} \frac{\partial \bar{v}_{1}}{\partial z} h^{\prime} \\
& +\rho \bar{v}_{1} \bar{v}_{1} \frac{\partial h^{\prime}}{\partial \alpha}+2 \rho \bar{v}_{1} \frac{\partial \bar{h}^{\prime}}{\partial \alpha} v_{1}^{\prime}+\rho \bar{v}_{1} \bar{v}_{2} \frac{\partial h^{\prime}}{\partial \alpha}+\rho \bar{v}_{1} \frac{\partial \bar{h}^{\prime}}{\partial z} v_{2}^{\prime} \\
& +\rho \bar{v}_{2} \frac{\partial \bar{h}}{\partial z} v_{1}^{\prime}+\bar{h} \frac{\partial p^{\prime}}{\partial \alpha}+\frac{\partial \bar{p}}{\partial \alpha} h^{\prime}+f \rho\left(\bar{v}_{1}^{2}+\bar{v}_{2}^{2}\right)^{1 / 2} v_{1}^{\prime} \\
& +f \rho\left(\bar{v}_{1}^{2}+\bar{v}_{2}^{2}\right)^{-1 / 2} \bar{v}_{1}^{2} v_{1}^{\prime}+f \rho\left(\bar{v}_{1}^{2}+\bar{v}_{2}^{2}\right)^{-1 / 2} \bar{v}_{1} \bar{v}_{2} v_{2}^{\prime} \\
& =-\left[\rho \bar{h} \bar{v}_{1} \frac{\partial \bar{v}_{1}}{\partial \alpha}+\rho \bar{h} \bar{v}_{1} \frac{\partial \bar{v}_{2}}{\partial z}+\rho \bar{h}_{\bar{v}} \frac{\partial \bar{v}_{1}}{\partial \alpha}+\rho \bar{h} \bar{v}_{2} \frac{\partial \bar{v}_{1}}{\partial \alpha}+\rho \bar{v}_{1} \bar{v}_{1} \frac{\partial \bar{h}}{\partial \alpha}\right. \\
& \left.+\rho \bar{v}_{1} \bar{v}_{2} \frac{\partial \bar{h}}{\partial z}+\bar{h}_{\frac{\partial \bar{p}}{\partial \alpha}}+f \rho\left(\bar{v}_{1}^{2}+\bar{v}_{2}^{2}\right)^{1 / 2} \bar{v}_{1}\right] \text {, }
\end{aligned}
$$




$$
\begin{aligned}
& \rho \bar{h}_{2} \frac{\partial v_{1}^{\prime}}{\partial \alpha}+\rho \bar{h} \frac{\partial \bar{v}_{1}}{\partial \alpha} v_{2}{ }^{\prime}+\rho \bar{v}_{2} \frac{\partial \bar{v}_{1}}{\partial \alpha} h^{\prime}+\rho \bar{h} \bar{v}_{2} \frac{\partial v_{2}^{\prime}}{\partial z} \\
& +\rho \bar{h} \frac{\partial \bar{v}_{2}}{\partial z} v_{2}{ }^{\prime}+\rho \bar{v}_{2} \frac{\partial \bar{v}_{2}}{\partial z} h^{\prime}+\rho \bar{h} \bar{v}_{1} \frac{\partial v_{2}^{\prime}}{\partial \alpha}+\rho \bar{h} \frac{\partial \bar{v}_{2}}{\partial \alpha} v_{1}{ }^{\prime} \\
& +\rho \bar{v}_{1} \frac{\partial \bar{v}_{2}}{\partial \alpha} h^{\prime}+\rho \bar{h} \bar{v}_{2} \frac{\partial v_{2}^{\prime}}{\partial z}+\rho \bar{h} \frac{\partial \bar{v}_{2}}{\partial z} v_{2}^{\prime}+\rho \bar{v}_{2} \frac{\partial \bar{v}_{2}}{\partial z} h^{\prime} \\
& +\rho \bar{v}_{1} \bar{v}_{2} \frac{\partial h^{\prime}}{\partial \alpha}+\rho \bar{v}_{1} \frac{\partial \bar{h}}{\partial \alpha} v_{2}{ }^{\prime}+\rho \bar{v}_{2} \frac{\partial \bar{h}_{2}}{\partial \alpha} v_{1}{ }^{\prime}+\rho \bar{v}_{2} \bar{v}_{2} \frac{\partial h^{\prime}}{\partial z} \\
& +2 \rho \bar{v}_{2} \frac{\partial \bar{h}}{\partial z} v_{2}^{\prime}+\bar{h} \frac{\partial p^{\prime}}{\partial z}+\frac{\partial \bar{p}^{\prime}}{\partial z} h^{\prime}+f \rho\left(\bar{v}_{1}^{2}+\bar{v}_{2}\right)^{\prime / 2} v_{2}^{\prime} \\
& +f \rho \bar{v}_{1} \bar{v}_{2}\left(\bar{v}_{1}^{2}+\bar{v}_{2}^{2}\right)^{-1 / 2} v_{1}^{\prime}+f \rho \bar{v}_{2}^{2}\left(\bar{v}_{1}^{2}+\bar{v}_{2}^{2}\right)^{-1 / 2} v_{2}{ }^{\prime} \\
& =-\left[\rho \bar{h}_{2} \frac{\partial \bar{v}_{1}}{\partial \alpha}+\rho \bar{h} \bar{v}_{2} \frac{\partial \bar{v}_{2}}{\partial z}+\rho \bar{h} \bar{v}_{1} \frac{\partial \bar{v}_{2}}{\partial \alpha}+\rho \bar{h} \bar{v}_{2} \frac{\partial \bar{v}_{2}}{\partial z}\right. \\
& \left.+\rho \bar{v}_{1} \bar{v}_{2} \frac{\partial \bar{h}}{\partial \alpha}+\rho \bar{v}_{2} \bar{v}_{2} \frac{\partial \bar{h}}{\partial \alpha}+\bar{h} \frac{\partial \bar{p}}{\partial z}+f \rho\left(\bar{v}_{2}^{2}+\bar{v}_{2}^{2}\right) / l^{1 / 2} \bar{v}_{2}\right] \text {, }
\end{aligned}
$$

where

$$
\begin{aligned}
& \bar{h}=h_{0}+\hat{h} \cdot\left(\bar{x}_{2}-\bar{x}_{1}, \bar{y}_{2}-\bar{y}_{1}, \bar{z}_{2}-\bar{z}_{1}\right), \\
& h^{\prime}=\hat{h} \cdot\left(x_{2}^{\prime}-x_{1}^{\prime}, y_{2}^{\prime}-y_{1}^{\prime}, z_{2}^{\prime}-z_{1}^{\prime}\right) .
\end{aligned}
$$

To formulate a finite element perturbation stiffness equation, we first arrange the nodal degrees of freedom in some convenient order in a column vector, as follows: 


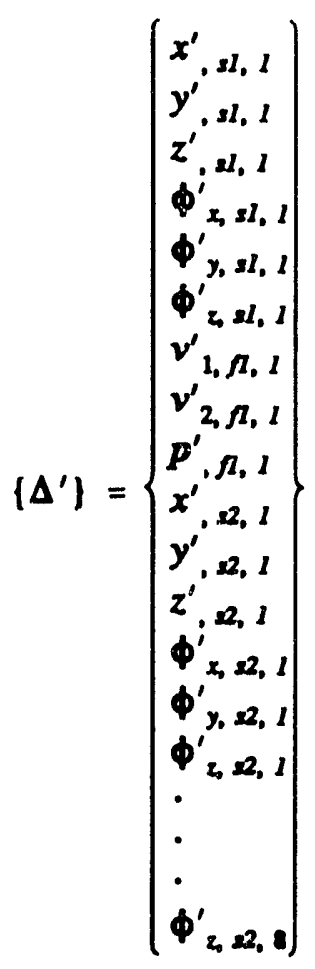

where $x^{\prime}, y^{\prime}, z^{\prime}$ denote the shell displacement variables; $\phi_{x}^{\prime}, \phi_{y}^{\prime}, \phi_{z}^{\prime}$ denote the shell rotational degrees of freedom; the subscript $s 1$ refers to the shell on the convex side of the fluid element; $f l$ refers to the fluid element; $s 2$ refers to the shell on the concave side of the fluid element; and the last numeric subscript refers to the node index that runs from 1 to 8 for the 8-node isoparametric quadralateral element. (The shell rotational degrees of freedom are included above for completeness, but they play no part in the coupling to the fluid in the present model and may be omitted from the fluid stiffness equation.) By introducing a matrix of interpolation functions,

$$
[N(r, s)],
$$

we can convert the nodal degrees of freedom into a vector of interpolated variables. In Eq. (14), $r$ and $s$ are the local element isoparametric spacial coordinates. The interpolation functions for the 8-node quadralateral element used in the present work are given, for example, by Bathe. ${ }^{10}$ Because the fluid differential equations involve both the fluid variables and their first derivatives, it is convenient to 
introduce a vector consisting of the zeroth derivative and the two first partial derivatives. Using the fluid pressure, $p^{\prime}$, as an example, we form the following equation:

$$
\left\{\begin{array}{c}
\cdot \\
\dot{p^{\prime}} \\
\frac{\partial p^{\prime}}{\partial \alpha} \\
\frac{\partial p^{\prime}}{\partial \alpha} \\
\cdot \\
\cdot
\end{array}\right\}
$$

where the vertical dots refer to the other fluid and shell variables. This vector of derivatives plays a role in the present formulation that is analogous to the strain vector in elastic finite element formulations. (Not all of these derivatives are actually needed for all of the variables for the present formulation.) To obtain the derivatives, we introduce (1) a derivative operator matrix $[D]$ that differentiates the interpolation function with respect to the local coordinates $(r, s)$ and $(2)$ an array [J] of Jacobians that converts the local derivatives into derivatives with respect to the global channel coordinates $(\alpha, z)$.

Next we form a matrir, $[C]$, containing the coefficients of the primed quantities in Eqs. (8) to (10) arranged in an order consistent with the vector Eq. (15). Then the system of Eqs. (8) to (10) can be expressed approximately in the form

$$
[C]\left[J[D][N(r, s)]\left\{\Delta^{\prime}\right\}=\{b\}\right. \text {, }
$$

where $\{b\}$ is the column vector consisting of the right-hand side of Eqs. (8) to (10). To use Galerkin's method with Eq. (16), we multiply from the left by an array $[N(r, s)]$ of Galerkin weighting functions of the same form as the interpolation functions and integrate over the element to obtain the element stiffness formulation 
The above formulation does not capture all of the steps needed to couple the fluid to the surrounding shells because it includes only the fluid equations. In addition, the shell equilibrium equations must be modified to include the fluid force on the shell given by

$$
\iint\left[N^{t}\right] p d \vec{A}
$$

where $\left[N^{*}\right]$ is an array of Galerkin weighting functions, $p$ is the fluid pressure, $\overrightarrow{d A}$ is a differential element of shell surface area (treated as a vector with the direction of the shell normal), and the integral is over the wetted surface of the shell element. Introducing barred and primed quantities as perturbations as before and deleting high-order terms,

$$
\iint\left[N^{\prime}\right] p d \vec{\Lambda}=\iint\left[N^{\prime}\right] \bar{p} d \vec{\Lambda}+\iint\left[N^{\prime}\right] \vec{p} d \vec{\Lambda}^{\prime}+\iint\left[N^{\prime}\right] p^{\prime} d \overrightarrow{\vec{A}}
$$

The first term on the right hand side of Eq. (19) is the ordinary pressure loading, and the second term is usually referred to as a pressure stiffness and must be added to the stiffness matrix because $d A^{\prime}$ is a function of the unknown shell nodal deflection corrections. Both the first and second terms occur normally in ordinary pressure loading in geometrically nonlinear structural mechanics. Thus, ABAQUS has facilities for calculating and assembling those terms. The ABAQUS facilities are used in the present work by introducing a dummy element to pick up the known fluid pressure estimate, $\bar{p}$, from ABAQUS and transfer it to a user-written pressure loading subroutine in the form required by ABAQUS. The third term, however, does not normally occur in structural mechanics, but it is needed here because the correction to the fluid pressure, $p^{\prime}$, is an unknown. It is therefore calculated and loaded into the stiffiness matrix as a part of the fluid element formulation.

To help clarify how the parts of the fluid stiffness element matrix fit together, refer to the schematic diagram of the matrix in Fig. 2. To achieve the form shown in Fig. 2, we must rearrange 


$\left[\begin{array}{c:c:c}s 1-s 1 & f l-s 1 & s 2-s 1 \\ \hdashline s 1-f 1 & f 1-f 1 & s 2-f 1 \\ \hdashline s 1-s 2 & f 1-s 2 & s 2-s 2\end{array}\right]$

Fig. 2. Sketch of the user element stiffness matrix including fluid and shell terms; $s 1$ is shell$1 ; f 1$ is fluid channel; $s 2$ is shell-2.

the order of the degrees of freedom from that shown in Eq. (13) to run through the nodal index first, i.e.: $\left(x^{\prime}{ }_{s, 1}, x^{\prime}{ }_{s 1,2}, \ldots\right)$.

Figure 2 deals with one fluid element, which we refer to in the following discussion as fluid element 1 or fluid-1, and with the two shell elements that enclose it, which we refer to as shell-1 and shell-2.

In Fig. 2, the submatrix $s I-s I$ represents the stiffnesses that are internal to shell-1 (the counterclockwise shell). These stiffnesses are left blank (zero) in the fluid element. When the elements are assembled, these blanks are filled in by ABAQUS with shell stiffnesses.

The submatrix $f l-s l$ represents forces originating in fluid-1 and acting on shell-1. These include in the present model only normal pressure forces and are obtained from the third term of Eq. (19).

The submatrix s2-s1 represents direct mechanical forces by shell-2 to shell-1 and is zero.

The submatrix sI-fl represents the effect of the deflection of shell-1 on the motion of fluid-1. In the present model, this effect occurs solely through the fluid channel thickness variable, $h$, in Eqs. (1)-(3). When Eq. (12) is substituted into Eqs. (8)-(10) and the usual Galerkin integrals are evaluated, the elements of submatrix $s 1-f 1$ are obtained.

The submatrix $f l-f l$ represents fluid-fluid interactions and is obtained directly from the linearized form of Eqs. (8)-(10).

The submatrix $s 2-f 1$ represents the effect of the deflection of shell-2 on the motion of fluid-1 and is the counterpart of $s 1-f l$ discussed above.

The submatrix $s 1-s 2$ is the counterpart of submatrix $s 2-s 1$ and is zero.

The submatrix $f 1-s 2$ represents fluid pressure forces on shell-2 and is obtained in the same way as submatrix $f l$-sl above.

The submatrix $s 2-s 2$ is the stiffness matrix for shell-2. Its value is left as zero in the fluid matrix and is filled in by ABAQUS when the shell element is assembled. 
The layout of the right-hand-side vector is analogous to the stiffness matrix. The shell terms are entirely supplied by ABAQUS at assembly time, and the fluid terms are supplied in the user fluid element subroutine. The dimension of the fluid element stiffness matrix is $[8(6+3+6)] \times[8(6+3+$ $6)]=120 \times 120$ where 8 is the number of nodes, 6 is the number of shell degrees of freedom per node, and 3 is the number of fluid degrees of freedom per node. If, however, the shell rotationai degrees of freedom are omitted, the fluid element stiffness matrix dimension is reduced to $72 \times 72$.

The complete fluid-shell structure is actually made up of hundreds of fuel plates and hundreds of fluid channels, and it is not feasible to include all of them in an analysis. Following Miller, ${ }^{4}$ we assunie that, for the most unstable form of disturbance, the shell deflection is periodic around the ring of the fuel element with a period of two shells and two fluid channels. Thus, we model with finice elements just two of the shells and two of the channels, and we impose periodic boundary conditions that couple fluid-2 back to shell-1. A complication in such a periodic boundary condition is that the angular orientation of shell-1 is slightly different from that of the unmodeled shell-3 that it replaces in the periodicity condition. Thus, some rotation of the displacements of shell-1 and of the forces on shell-1 is necessary when it is used to replace shell-3. It was found in the present work that the most convenient method of handling this rotation was to lay out the finite element grid so that the two shells and two fluid channels that are modeled all overlay one another. Then, only one fluid element need be developed, and that element incorporates a built-in rotation whenever reference is made to displacements or to forces from either adjoining shell. 


\section{BOUNDARY CONDITIONS}

The fluid inlet flow is assumed to be guided straight into the cilannel by ducting or vanes, so the transverse velocity, $v_{1}$, is zero at the inlet.

At the channel entrance, the fluid pressure is related to the fluid axial velocity by the modified Bemoulli equation

$$
p+\frac{1}{2}\left(1+C_{c}\right) \rho v_{2}^{2}=p_{m}+\frac{1}{2} \rho v_{m}^{2}
$$

where $p$ and $v_{2}$ are the pressure and axial velocity just inside the channel entrance, $p_{u}$ and $v_{u}$ are the pressure and axial velocity in the entrance plenum just upstream of the entrance contraction, and $C_{c}$ is a contraction loss coefficient. In the ANS, the fuel plate leading edges will be rounded, so the value $C_{c}=0.04$ recommended by Vennard ${ }^{11}$ is used in the present work. ABAQUS includes the capability for nonlinear user-written boundary condition subroutines, so Eq. (20) can be implemented.

At the channel exit, there is a sudden expansion in cross section. At a sudden expansion in a single channel, the Borda-Camot ${ }^{12}$ equation is usually recommended:

$$
p+\frac{1}{2} \rho v_{2}^{2}=p_{d}+\frac{1}{2} \rho v_{d}^{2}+\frac{1}{2} \rho\left(v_{2}-v_{d}\right)^{2},
$$

where $p$ and $v_{2}$ are the fluid pressure and axial velocity just upstream of the expansion, and $p_{d}$ and $v_{d}$ are the pressure and axial velocity in the exit plenum downstream of the expansion.

Associated with this equation is a standard derivation. ${ }^{12} \mathrm{~A}$ fundamental assumption of the derivation is (1) at a channel section located an infinitesimal distance downstream of the expansion, the fluid pressure is uniform across the section and (2) the fluid pressure in the upstream channel drops smoothly to the section pressure as the expansion is approached. Borda's assumption is also the basis of the theory of jet pumps and ejectors in which two fluid streams traveling at different velocities are introduced into a common channel. Applying Borda's assumption to the present two-channel geometry, we conclude that the pressure is equal and uniform at the exit of the two channels. In incompressible hydrodynamics, the fluid pressure need only be specified within an additive constant. 
Thus it is convenient in the present analysis to set the uniform channel exit pressure to zero and to measure all pressures relative to that point.

The lateral edges of the fuel plates are built into nonpermeable sidewalls. The corresponding transverse fluid velocity boundary condition is taken as zero.

Note that the additional condition of a zero axial velocity at the lateral channel edges is omitted. In a real channel, viscous turbulent boundary layers (with a thickness on the order of the channel thickness) will develop at the edges, and the axial velocity will drop to zero at the surface within the boundary layer. The real turbulent edge effects are quite complicated and involve secondary flows. The present equations (which do not incorporate viscosity or a detailed study of turbulence) are not capable of resolving the fluid edge effects, so the condition of zero axial velocity must be omitted.

The boundary conditions applied to the solid shell elements consist mainly of periodicity constraints on the edges of the sidewall segments to simulate modeling of a segment of a complete circular ring of fuel plates. Because ABAQUS uses global Cartesian coordinates for the displacements by default, it is necessary to rotate the local coordinates along the edges so that they are aligned with the local radial and azimuthal directions before applying these constraints.

These periodicity boundary conditions leave the shell assembly free with respect to rigid body rotation about the axis of the assembly and with respect to rigid body displacement axially. To constrain these motions and ensure that the structure is statically determinate, one node on one of the sidewalls must be constrained against azimuthal and axial motion. The other sidewall is allowed free rotation about the axis in accordance with the ANS design configuration.

Figure 3 shows the finite element grid used for the present calculations. The grid appears foreshortened because of the viewing angle chosen for this figure. The actual dimensions are given in the next section. Only the shell elements (not the fluid elements) are plotted by ABAQUS. Furthermore, the two involute plates included in the grid overlay one another as discussed earlier. Thus all that can be seen is one involute plate and the segments of the sidewall rings that are attached to both ends. Each involute plate is divided into $16 \times 328$-node isoparametric curved shell elements. There are 37,812 degrees of freedom in this model. The running time is about 70 min per Newton iteration on an IBM RISC/6000 Model 320H workstation. 


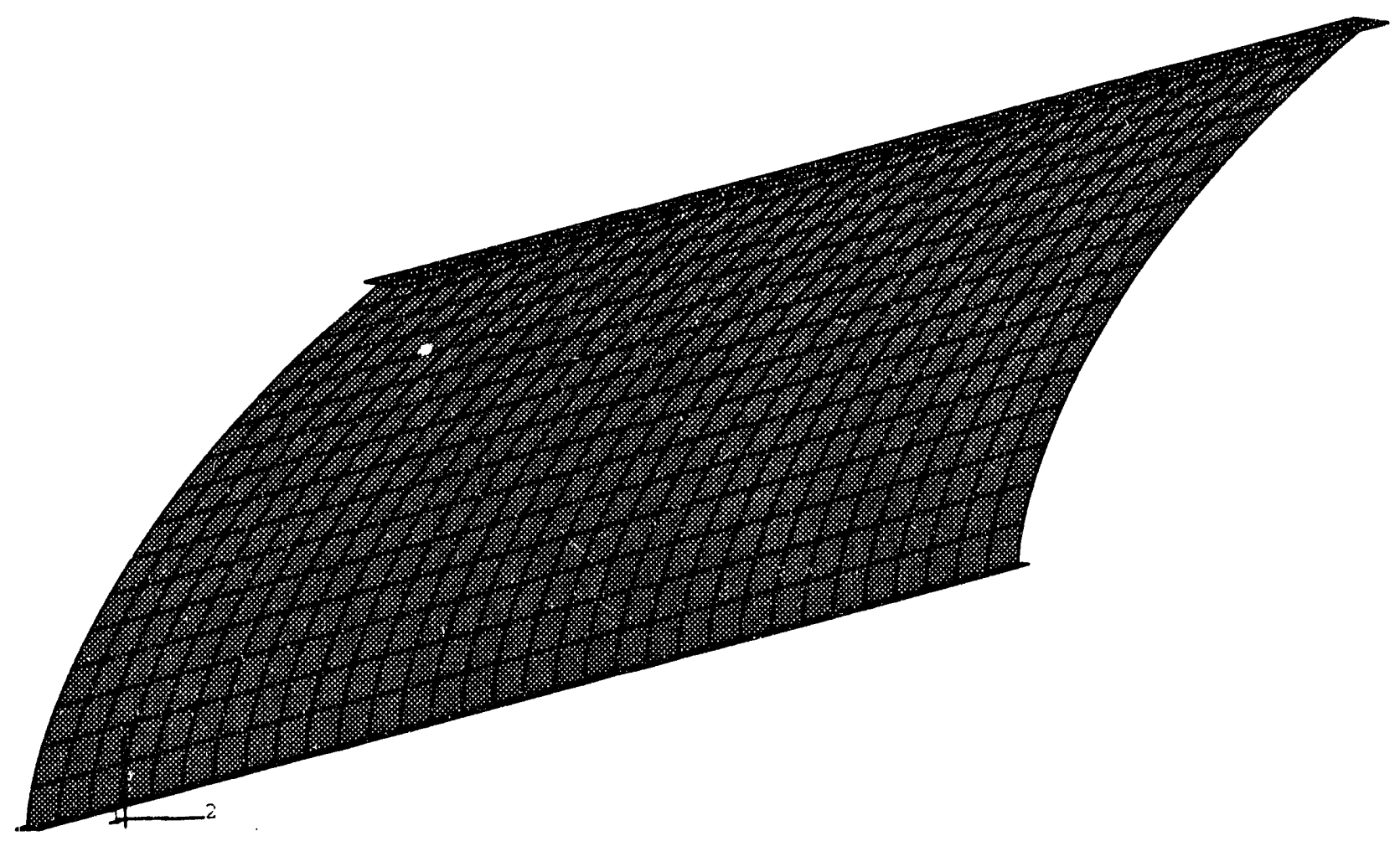

Fig. 3. Finite element grid. Only one plate is visible; the fluid elements are not shown. 


\section{ANALYSIS OF AN IMPERFECT CHANNEL}

For the present study, the following nominal dimensions and properties were used.

$$
\begin{array}{ll}
\text { involute inner radius } & =175 \mathrm{~mm} \\
\text { involute outer radius } & =235 \mathrm{~mm} \\
\text { plate length } & =527 \mathrm{~mm} \\
\text { plate thickness } & =1.27 \mathrm{~mm} \\
\text { fluid channel thickness } & =1.27 \mathrm{~mm} \text { (nominal) } \\
\text { fluid density } & =1096.65 \mathrm{~kg} / \mathrm{m}^{3} \text { (heavy water) } \\
\text { fluid viscosity } & =6.53 \times 10^{-4} \mathrm{Pas} \\
\text { plate elastic modulus } & =6.89 \times 10^{10} \mathrm{~Pa} \text { (aluminum) } \\
\text { plate Poisson's ratio } & =0.33
\end{array}
$$

One reason for developing a nonlinear fluid finite element was to analyze a fuel element that included a noninfinitesimal imperfection. The imperfection of interest consists of an error in fluid channel thickness relative to the nominal value given above. For the imperfect fuel element, we take the unperturbed thickness, $h_{0}$, of fluid channel 1 to be $(1.27 \mathrm{~mm}+\delta)$ and the thickness of fluid channel 2 to be $(1.27 \mathrm{~mm}-\delta)$, where $\delta$ is varied during the study. Note that $\delta$ is assumed constant along the length and width of one channel in the present study, whereas a real imperfection would likely have a complicated spacial distribution. Because we impose periodic boundary conditions in this work, the channel thickness imperfection is implicitly assumed to altemate at $\pm \delta$ around the remainder of the ring.

In analyzing the present problem, we begin with the perfect structure at a fluid velocity well below the buckling velocity, for which the solution is zero perturbation. In the first load step, the imperfection $(\delta)$ is increased to its target value. This increase is accomplished by setting the value of $\delta$ proportional to a dummy time, which $A B A Q U S$ defines as running from 0 to 1.0 during the first step, and which is passed along to the user (fluid) element subroutine. In the second load step, time runs from 1.0 to $2.0, \delta$ is held fixed, and the nominal fluid velocity (before perturbation) is adjusted (linearly in time) from its low starting value to a value above the linear buckling limit. ABAQUS then controls the dummy time increments to the largest values consistent with continued convergence of Newton's method. As the buckling threshhold is approached, these increments get smaller and smaller. 


\section{NONLINEAR DEFLECTION RESULTS}

Relevant results of the analyses are presented in Fig. 4, which shows the maximum plate deflection anywhere on the two-plate structure plotted against the nominal coolant velocity for values of the imperfection of $\delta=0 \%, 1 \%, 10 \%$ and $30 \%$ of the nominal fluid gap.

For $\delta=0 \%$, the horizontal axis is always a solution (although not always a stable one). In addition, at a velocity of about $45 \mathrm{~m} / \mathrm{s}$, a bifurcation orcurs. Rising out of the bifurcation is a second branch of the solution that curves back to the left. Thus, at a coolant velocity of $40 \mathrm{~m} / \mathrm{s}$, for example, at least two solutions exist, one of zero deflection and one with a maximum deflection of about $0.00045 \mathrm{~m}$ (about $35 \%$ of the fluid gap).

For an imperfection of $\delta=1 \%$, the calculated deflection for low velocities is close to the horizontal axis, but as the bifurcation velocity is approached, the $\delta=1 \%$ line curves up sharply, reaching an infinite slope at a nominal coolant velocity of about $44 \mathrm{~m} / \mathrm{s}$. Thereafter, the $1 \%$ line doubles back to the left, close to the $\delta=0 \%$ line.

For values of $\delta$ of $10 \%$ and $30 \%$ of the fluid gap, the deflection at low coolant velocity is much larger, but qualitatively the lines are similar to the $1 \%$ line. In particular, all three deflection curves for an imperfect structure include a point of infinite slope.

At the point of infinite slope, there is a possible (differential) change in deflection without any change in velocity or in imperfection. At such a point, the differential stiffness of the fluid-shell assembly drops to zero. (The negative stiffness caused by the fluid interaction just offsets the positive elastic stiffness of the plates.) A wide line is drawn on Fig. 4 approximately through the points of infinite slope. Below and to the left of the wide line, the net stiffness is positive so that if a shell is perturbed from its equilibrium position by a small amount and then released, elastic forces will retum it to equilibrium. Atove and to the right of the wide line, the net stiffness is negative, and if a shell is perturbed from its equilibrium position (using the buckling mode shape) the dominant fluid forces will drive it further from equilibrium. Thus, the wide line is the nonlinear stability boundary.

If we take the maximum credible imperfection to be $10 \%$ and the maximum allowable nominal velocity to be $25 \mathrm{~m} / \mathrm{s}$, then the maximum plate deflection induced by the fluid is about $0.03 \mathrm{~mm}$. Note that the $10 \%$ imperfection amounts to $0.127 \mathrm{~mm}$ for the channel or $0.0635 \mathrm{~mm}$ for each plate. Thus, the maximum fluid-induced deflection is less than half of the imperfection at $25 \mathrm{~m} / \mathrm{s}$. Furthermore, the fluid-induced deflection is directed opposite to the imperfection. That is, if the imperfection acts to partially close up a channel, the fluid-induced deflection acts to open it up again. 


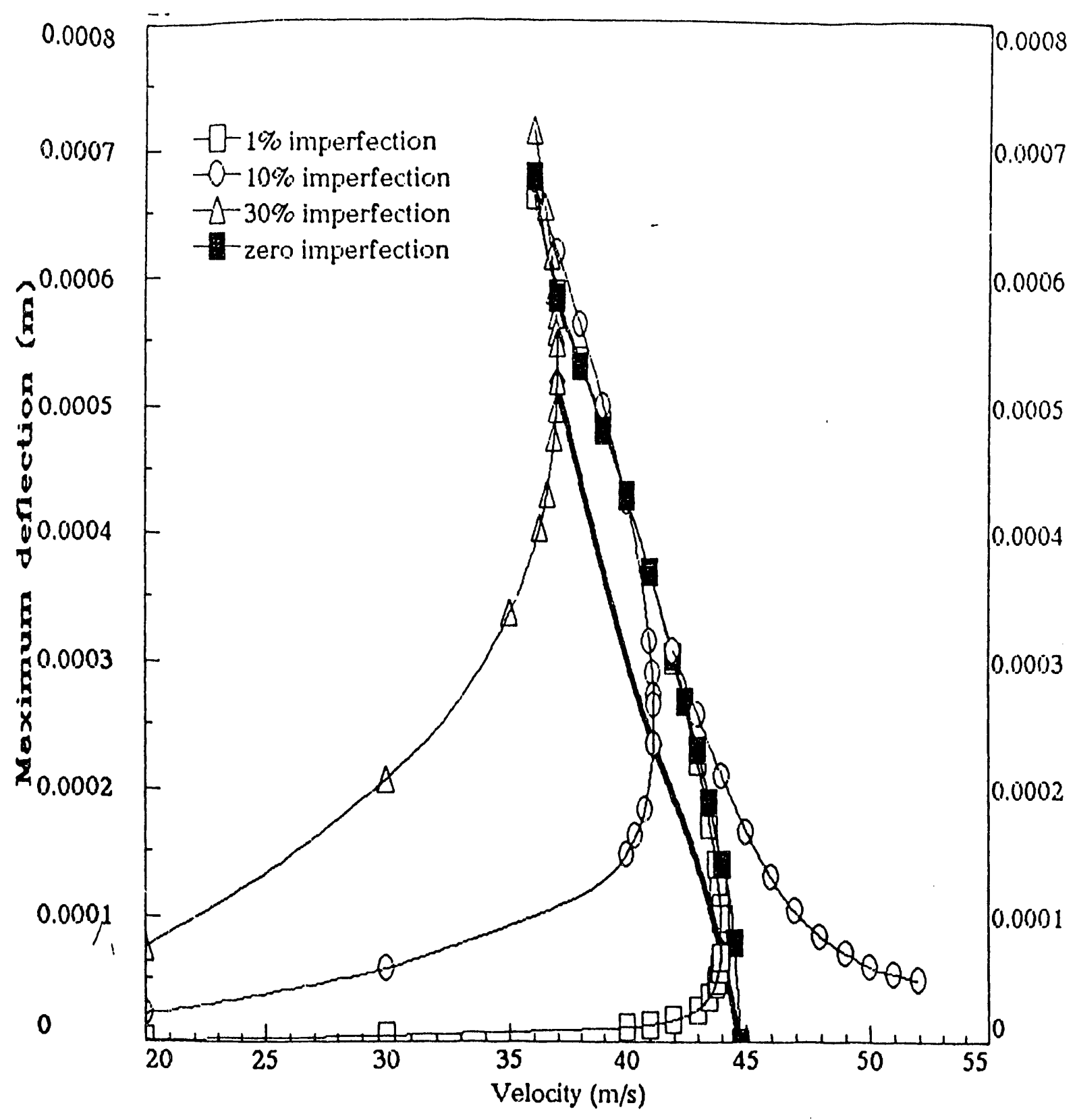

Fig. 4. Maximum deflection over the complete structure plotted against nominal coolant velocity for several values of imperfection. 
Note that the response to the imperfection calculated in this report is the opposite of the response to a perturbation discussed by Miller. ${ }^{4}$ Miller argues that if a perturbation tends to close up a channel, the fluid forces will make the plates move still closer. However, in the present work, if the imperfection tends to close up the channel, the fluid forces will tend to open it. (Swinson ${ }^{13}$ has also concluded that in a channel with a uniform imperfection that tends to close the channel, the fluid forces will tend to open it.) The key distinction is between a localized perturbation in a long channel as envisioned by Miller, and a uniform imperfection that extends the entire length of the channel as assumed in this work.

In the present work, we begin with a uniform imperfection that, let us say, tends to close the channel. Then the fluid forces begin to produce a (buckling) perturbation that tends to open the channel. But the buckling perturbation is mainly localized near the entrance (see Fig. 5) and therefore follows Miller's theory. That is, the opening up of the channel near the entrance by the buckling perturbation produces local fluid forces that tend to open the channel still further (near the entrance), and the process feeds on itself and leads on to plate collapse if the fluid velocity is high enough.

Figure 4 shows only the deflection for one of the plates. When the plotted deflection is small (compared to the fluid gap), the deflection of the opposite plate is approximately equal in magnitude and opposite in direction. When the plotted deflection is large, the deflection of the opposite plate is about half of that plotted. (As the deflection and fluid forces become large, nonlinear effects tend to increase the stiffness of the plate that is put into membrane tension and to decrease the stiffness of the plate that is put into membrane compression.)

The plate mode shape deflection is typically gieatest near the fluid entrance (see Fig. 5). An axial section of the plot usually shows no zeros for this lowest buckling mode. A transverse section plot shows an S-shape with one interior zero. This S-shape is the characteristic response of the involute plates even to a uniform pressure loading and has also been obtained experimentally. ${ }^{14}$ 


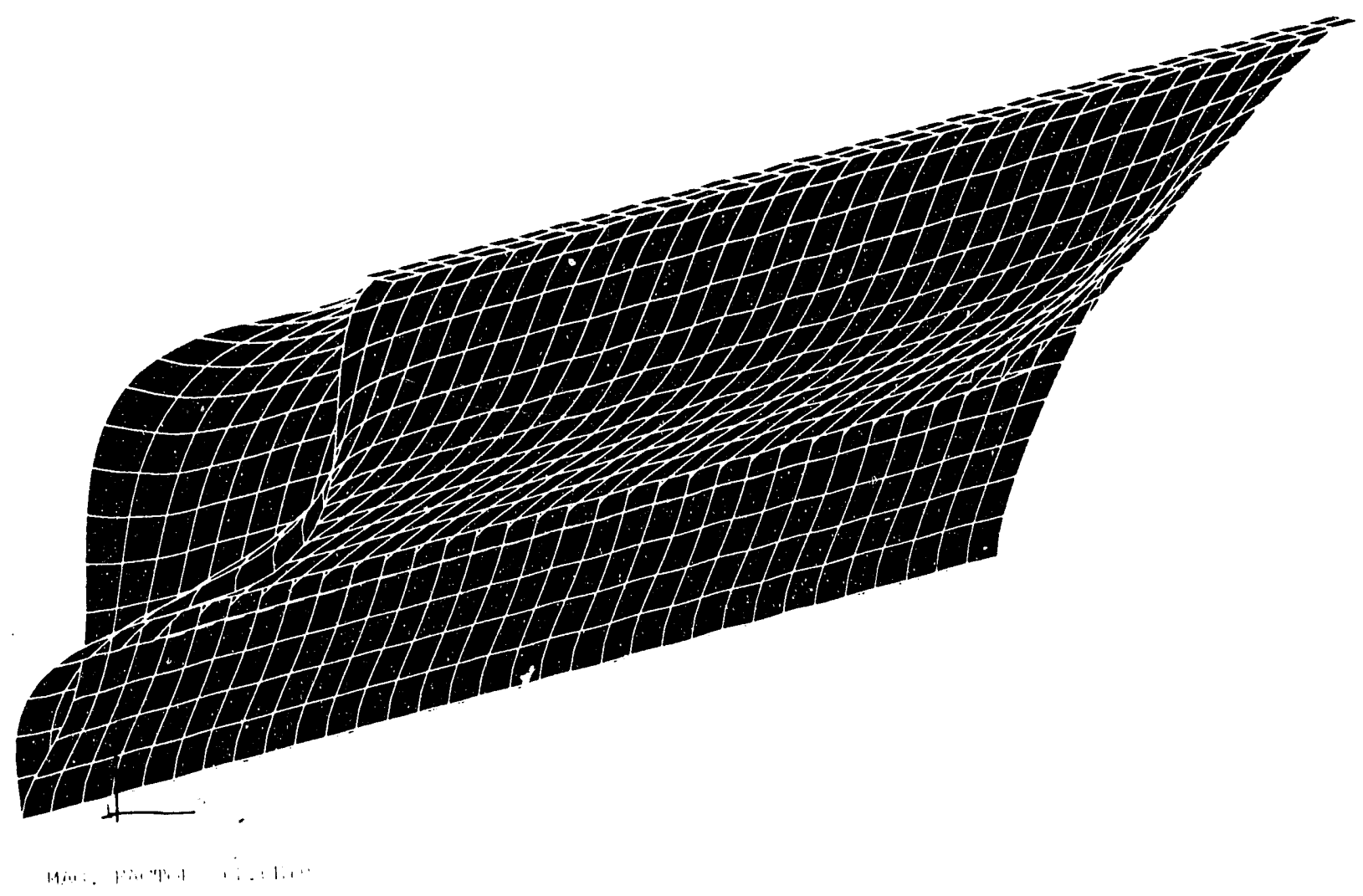

Fig. 5. Illustration of the mode shape plotted as a deformed grid plot for an imperfection of $10 \%$ and a nominal coolant velocity of $40 \mathrm{~m} / \mathrm{s}$. The plate deflection is magnified 100 times for this illustration. The plates are plotted as if they overlayed one another in the undeformed state. The fluid entrance is at the left. 


\section{SUMMARY AND CONCLUSIONS}

The hydraulic buckling instability of the involute fuel plates and coolant channels of the ANS nuclear reactor is analyzed nonlinearly using the commercial ABAQUS structural finite element program along with a user-written hydraulic channel element for the fluid. Particular attention is given to the effect of an imperfection in the fluid channels. The imperfection studied consists of an error in channel thickness that is uniform within any one channel but that varies from one channel to the next. The family of curves giving the fuel plate deflection vs coolant velocity and imperfection magnitude shows a bifurcation point at about $45 \mathrm{~m} / \mathrm{s}$ coolant velocity. At the design coolant velocity of $25 \mathrm{~m} / \mathrm{s}$, the maximum predicted fluid-induced deflection of the plates is smaller than the magnitude of the imperfection itself and opposite in direction.

The uniformly distributed imperfection studied herein is not believed to be the most dangerous form. Rather, an imperfection shape close to the buckling mode shape is expected to be more dangerous. The buckling mode shape exhibits a plate deflection that is greatest near the fluid entrance. 


\section{REFERENCES}

1. G. L. Copeland et al., Advanced Neutron Source Final Preconceptual Reference Core Design, ORNL/TM-11234, Martin Marietta Energy Systems, Inc., Oak Ridge Natl. Lab., August 1989.

2. W. K. Stromquist and O. Sisman, High Flux Reactor Fuel Assemblies Vibration and Water Flow, ORNL-50, Oak Ridge Natl. Lab., June 1948.

3. W. F. Swinson et al., "Fuel Plate Stability Experiments and Analysis for the Advanced Neutron Source," Proceedings of the ASME 3rd International Symposium on Flow-Induced Vibration and Noise, November 1992.

4. D. R. Miller, "Critical Flow Velocities for Collapse of Reactor Parallel-Plate Fuel Assemblies," $J$. Eng. Power, Trans. ASME, 83-95, April 1960.

5. F. T. Binford and E. N. Cramer, The High Flux lsotope Reactor, Volume I, Functional Description, ORNL-3572, Union Carbide Corp., Nuclear Div., Oak Ridge Natl. Lab., May 1964.

6. R. C. Gwaltney and C. R. Luttrell, "Critical Flow Velocities for Involute Parallel Plate Assemblies," Transactions of the American Nuclear Society and the European Nuclear Society. 1988 International Conference on Nuclear Fission: Fifty Years of Progress in Energy Security and the Topical Meeting TMI-2 Accident: Materials Behavior and Plant Recovery Technology 57, 298, TANSAO57 1-548 (1988).

7. R. J. Scuvazzo, Hydraulic Instability of Flat Parallel Plate Assemblies, Ph.D. Dissertation, University of Pittsburgh, 1962.

8. G. E. H. Smissaert, Hydroelastic Instabilities in Fuel Plate Elements, Ph. D. Dissertation, Pennsylvaria State University, 1966.

9. W. K. Sartory, Analysis of Hydraulic Instability of ANS Involute Fuel Plates, ORNL/TM-11580, Martin Marietta Energy Systems, Inc., Oak Ridge Natl. Lab., November 1991.

10. K.-J. Bathe, Finite Element Procedures in Engineering Analysis, Prentice-Hall, Englewood Cliffs, 1982.

11. J. K. Vennard, Elementary Fluid Mechanics, 317, 4th Ed., Wiley, New York, 1961.

12. H. C. Schutt, "Losses of Pressure Head Due to Sudden Enlargement of a Flow Cross Section," Trans. ASME 51, Part 1, 83-87 (1929).

13. F. W. Swinson, personal communication, Oak Ridge Natl. Lab., 1992.

14. R. D. Cheverton and W. H. Kelley, Experimental Investigation of HFIR Fuel Plate Deflections Induced by Temperature and Pressure Differentials, ORNL/TM-2325, Union Carbide Corp., Nuclear Div., Oak Ridge Natl. Lab., August 1968. 


\section{Internal Distribution}

1. C. W. Alexander

2. D. J. Alexander

3. R. R. Allen

4. E. E. Alston

5. J. L. Anderson

6. B. R. Appleton

7. R. E. Battle

8. R. S. Booth

9. W. W. Bowman

10. R. A. Brown

11. G. J. Bunick

12. J. H. Campbell (5)

13. P. F. Cento

14. N. C. J. Chen

15. K K. Chipley

16. J. A. Clinard

17. J. E. Cleaves

18. J. T. Cleveland

19. G. L. Copeland

20. B. L. Corbett

21. J. M. Corum

22. J. R. Dixon

23. F. F. Dyer

24. D. K. Felue

25. R. E. Fenstermaker

26. M. L. Gildner

27. H. A. Glovier

28. R. C. Gwaltney

29. R. M. Harrington

30. J. B. Hayter

31. W. R. Hendrich

32. S. E. Holliman

33. M. M. Houser

34. D. T. Ingersoll

35. R. L. Johnson (4)

36. J. E. Jones, Jr.

37. M. Kaminaga

38. R. A. Lillie

39. M. A. Linn

40. A. T. Lucas

41. C. R. Luttrell

42. J. A. March-Leuba

43. B. S. Maxon
44. G. T. Mays

45. S. V. McGrath

46. T. J. McManamy

47. G. R. McNutt

48. J. T. Mihalczo

49. B. H. Montgomery

50. R. M. Moon

51. D. G. Morris

52. R. E. Pawel

53. H. R. Payne

54. F. J. Peretz

55. C. C. Queen

56. S. Raman

57. C. T. Ramsey

58. J. S. Rayside

59. J. P. Renier

60. J. B. Rol rto

61. T. L. Ryan

62. W. K. Sartory

63. D. L. Selby

64. H. B. Shapira

65. M. Siman-Tov

66. B. R. Smith

67. W. F. Swinson

68. R. P. Taleyarkhan

69. D. W. Thiesen

70. S. R. Tompkins

71. P. B. Thompson

72. K. R. Thoms

73. D. B. Trauger

74. B. D. Warnick

75. C. D. West

76 J. L. Westbrook

77. D. M. Williams

78. B. A. Worley

79-80. G. T. Yahr

81. G. L. Yoder

82. ORNL Patent Office

83. Central Research Library

84. Document Reference Section

85. Y-12 Technical Library

86-87. Laboratory Records

88. Laboratory Records (RC) 


\section{External Distribution}

86. R. Awan, U.S. Department of Energy, NE-473, Washington, DC 20585.

87. C. L. Christen, DRS/Hundley Kling Gmitter, FEDC, MS-8218, P. O. Box 2009, Oak Ridge, TN 37831-8218.

88. R. A. Edlund, U.S. Department of Energy, Oak Ridge Field Office, FEDC, MS-8218, P. O. Box 2009, Oak Ridge, TN 37831-8218.

89. R. R. Fullwood, Brookhaven National Laboratory, Upton, NY 11973.

90. W. R. Gambill, Route 5, Box 220, Clinton, TN 37716.

91. B. Gupta, AECL Technologies, 1155 Metcalfe Street, 2nd Floor, Montreal, Quebec, Canada H3B 2V6.

92. A. F. Henry, Professor, Department of Nuclear Engineering, Massachusetts Institute of Technology, 77 Massachusetts Avenue, Cambridge, MA 02139.

93. R. A. Hunter, Director, Office of Facilities, Fuel Cycle, and Test Programs, Nuclear Energy Division, U.S. Department of Energy, NE-47, Washington, DC 20585.

94. L. C. Ianniello, Acting Associate Director, Office of Basic Energy Sciences, Office of Energy Research, U. S. Department of Energy, ER-10, Washington, DC 20585.

95. T. L. Kerlin, University of Tennessee, College of Engineering, 315 Pasqua Engineering Building, Knoxville, TN 37996-2300.

96. J. A. Lake, Manager, Nuclear Engineering and Reactor Design, Idaho National Engineering Laboratory, P. O. Box 1625, Idaho Falls, ID 83415.

97. W. F. Manning, ANS Project, U.S. Department of Energy, Oak Ridge Field Office, FEDC, MS-8218, P. O. Box 2009, Oak Ridge, TN 37831-8218.

98. J. E. Mays, Research and Test Reactor Fuel Elements, Babcock and Wilcox Co., P. O. Box 785, Lynchburg, VA 24505.

99-100. W. E. Meek, Project Manager, Gilbert/Commonwealth, Inc., P. O. Box 1498, Reading, PA 19603.

101. J. P. Mulkey, U.S. Department of Energy, NE-473, Washington, DC 20585.

102. W. T. Oosterhuis, Materials Sciences Division, Office of Basic Energy Sciences, Office of Energy Research, U.S. Department of Energy, ER-132, Washington, DC 20585.

103. J. M. Ryskamp, Idaho National Engineering Laboratory, P. O. Box 1625, Idaho Falls, ID 83415-3885.

104. J. L. Snelgrove, Coordinator, Engineering Applications, RERTR Program, Argonne National Laboratory, 9700 South Cass Avenue, Argonne, IL 60439.

105. I. Thomas, Director, Materials Science Division, Office of Energy Research, U.S. Department of Energy, ER-13, Washington, D.C. 20585.

106. J. M. Warren, Gilbert/Commonwealth, Inc., 1055 Commerce Park Drive, Suite 200, Oak Ridge, TN 37830.

107. D. K. Wilfert, ANS Project, U. S. Department of Energy, Oak Ridge Field Office, FEDC, MS-8218, P. O.Box 2009, Oak Ridge, TN 37831-8218.

108. P. W. Winkler, Air Products and Chemicals, Inc., 7201 Hamilton Boulevard, Allentown, PA 18195-1501.

109. H. G. Wood, III, Associate Professor, Department of Mechanical and Aerospace Engineering, Thornton Hall, University of Virginia, Charlottesville, VA 22901

110. Office of Assistant Manager for Energy Research and Development, U.S. Department of Energy, Oak Ridge Field Office, P.O. Box 2001, Oak Ridge, TN 37831-2001

111-112. Office of Scientific and Technical Information, P.O. Box 62, Oak Ridge, TN 37831. kkd/revised 3/30/93 

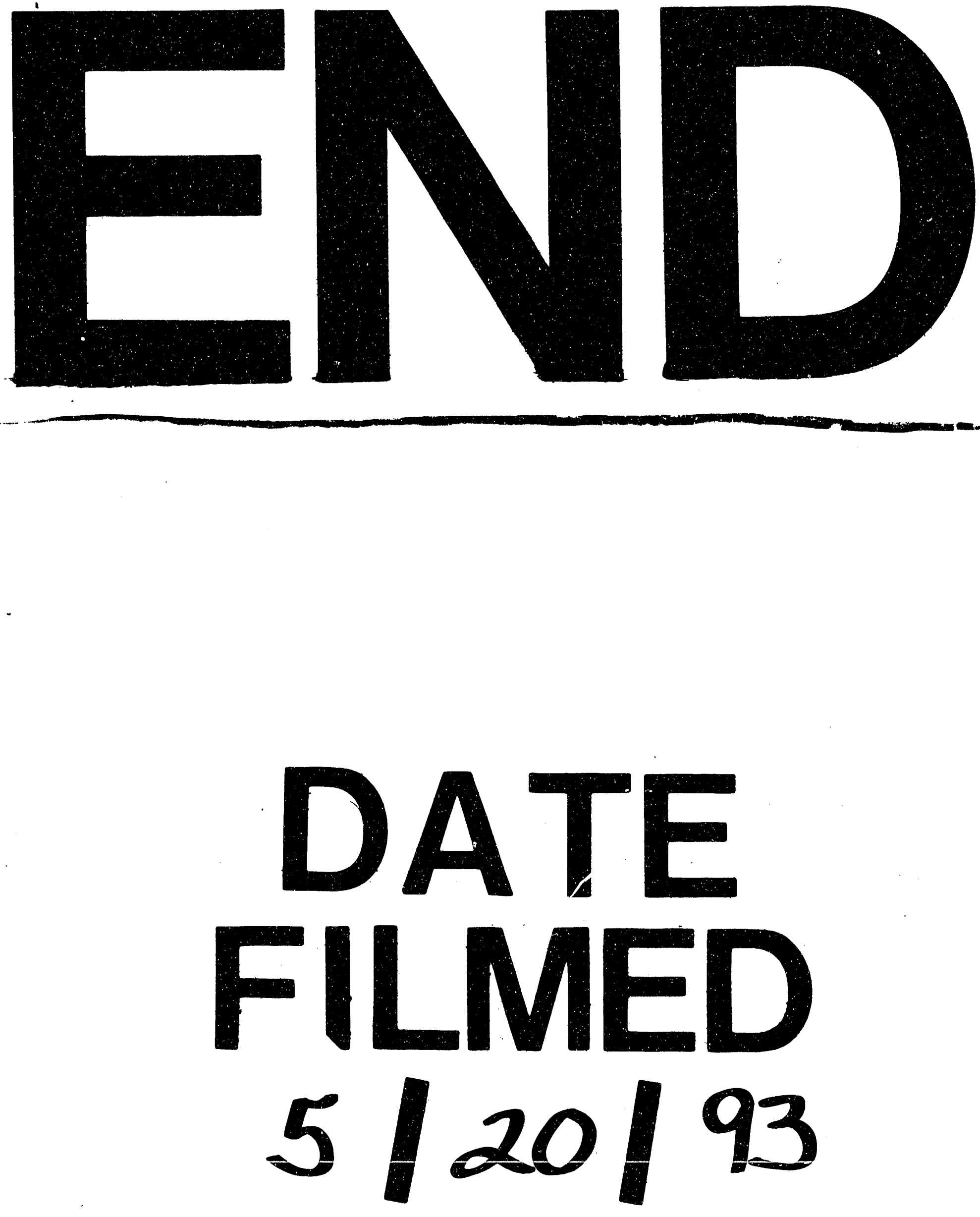
